\title{
NUMBER PROBLEMS IN CHILDREN*
}

\author{
Ana T. Pérez-Leroux \\ University of Toronto
}

\section{Introduction}

Work on nominal reference in children has identified contexts where young children seem to have difficulty with number marking in comprehension. Johnson et al's (2004) study uncovered an intriguing fact about verbal person/number: despite English-speaking children early ability to use it in production, they do not seem to be using it in comprehension. For the purpose of describing development in mainstream dialects of English, they tested children's capacity to understand sentences where number of the subject is hidden in pronunciation, and number interpretation depends on processing agreement on the verb, as (1). Reliable discrimination between these sentences emerged by the age of 5 but not before. The explanation for these errors may lie on: a) problems with processing surface morphology in a language that does not reliably encode number in the verbal system, b) aspects of syntactic computation of agreement system which may present asymmetric demands in production and comprehension, or c) a problem of parametric discontinuity in the syntaxsemantics interface of number.

The first goal of this paper is to examine whether this developmental number problem occurs in other languages. The present study considers children's comprehension of comparable sentences in Spanish, as in (2) a language with a robust, morphologically uniform verbal agreement paradigm. This could test whether insensitivity in number on the verb was due to low strength of the processing cue in English. The second goal is to consider some implications of this sort of semantic problems for certain versions of the strong continuity hypothesis in language acquisition. I argue that number insensitivity can create pockets of parametric discontinuity in the grammar.
a. The cat sleeps on the bed.
b. The cats sleep on the bed.
(2) a. Duerme en la cama.
b. Duermen en la cama (Spanish) sleep-3PL on the bed

\section{Discontinuity and parametrization in number}

\subsection{Continuity and discontinuity in child development}

A fundamental extension of Chomsky's innateness claims is the continuity hypothesis, which states that the problem-space of language acquisition can be restricted with the assumption that children's linguistic substantives (categories

\footnotetext{
* For correspondence, please contact A.T. Pérez-Leroux, Univ. of Toronto, 73 Queen's Park Crescent, Toronto, ON M5S 1K7, Canada, at.perez.leroux@utoronto.ca

Actes du congrès annuel de l'Association canadienne de linguistique 2005.

Proceedings of the 2005 annual conference of the Canadian Linguistic Association.

(C) 2005 Jean Linguist
} 
and computational processes) are fundamentally the same as those in the adult grammar. In Pinker's (1984, 1989) formulation, the strong continuity hypothesis held that that children's patterns of grammatical errors reflect instances of possible, although possibly non-target human grammars (Pinker 1984, 1989). The weak view of continuity held that functional categories developed through experience (Lebeaux 1988). Strong continuity was considered by some as more parsimonious and hence, preferable, but those that believed in parametrization in functional structure across languages, weak continuity was seen as necessary. The continuity debate gave impetus to a substantial volume of research on telegraphic speech. This work produced two uncontroversial results: one, children's syntactic pattern are parametrically differentiated from the onset of word combinations, and two, there is indirect but strong evidence that children have full clausal structure from the outset (see Guasti 2002 for a review). These data led to the strongest version of continuity, the very early parameter setting (VEPS). This hypothesis states that children have already set the parameters of the target language by the time of onset of speech. The emphasis on early parameter setting has minimized discussion on parametric discontinuity, with certain exceptions (Rizzi 2002, Snyder and Roeper 2003, and others).

Continuity-based approaches have a reduced inventory of possibilities to explain divergence between children's and adults linguistic behaviors: lack of attainment of parametric target, performance capacities (where the child has the target representation but is unable to use it reliably), or pragmatics capacities (where the child might have the target representation but not complete mastery of the pragmatic conditions that make a structure obligatory). Let's consider each in turn.

There are theoretical reasons against treating pragmatics as a generalized account of divergent linguistic behavior in children. The two innately specified aspects of language and language development. One aspect, the computational system, or narrow faculty of language, is specific to grammar and possibly unique to humans (Hauser et al 2002). The other aspect relates to the ability to represent mental phenomena and social interaction (Tager-Flusberg 1997), an ability that transcend our species but reaches high levels of complexity in it. Under this second aspect we include intentionality, joint attention capacities, and theory of mind, all of which are the building blocks of pragmatics. The core of these cognitive components is not language-specific, nor culture-specific. Therefore, there is no a priori basis to favor pragmatic discontinuity over parametric discontinuity as an account for development. Current data on pragmatic factors in early grammar suggest the opposite: children have patterns of subject and object omissions that reveal deep sensitivity to pragmatic factors (Serratrice et al 2004). Last, there are no theory-internal constraints that give explanatory primacy to pragmatic discontinuity. In fact, various theory-driven proposals assume that children make use of discourse (D-linking) to compensate for gaps in the grammar, such as that in Borer and Rohrbacher (2002).

Let's now turn to performance. While there are demonstrable differences on language processing in children as compared to adults (Trueswel et al 1999, and other), it is not clear how these make specific predictions about the type of grammatical discontinuities we consider here. Performance as an underdeveloped construct makes a weak last-resort solution to the problem of 
grammatical divergence in children. In fact, what we know about children's processing of linear associations shows remarkable capacities: recent findings that infants as young as 7 months have strong capacities for extracting distributional contingencies from limited exposure to input (Saffran et al 1996), and can make algebraic inferences about orderings that go beyond the actual segments (Marcus et al 1999). In other words, pre-lingual babies have all the capacities needed to uncover major word order facts, as they do.

The whole empirical evidence for early parameter setting phenomena lies on phenomena that can be acquired on the basis of learning the surface distribution of the language alone: null subject parameter (Valian 1990, Grinstead 1994), Verb movement (Pierce 1992, Verrips and Weissenborn 1992), subject inversion in interrogatives (Perez-Leroux 1993, 1999). This leaves open the question of parametric differences that go beyond surface distribution. In regards to this issue, Pérez-Leroux, Schmitt and Munn (2002, in prep) propose that acquisition of parameters of the target language involve three different types of learning: acquisition of gross distributional facts of the language (identification of major distributions), gross semantic (identification and fast mapping of main elements of the functional inventory), and acquisition of fine semantic facts (which involves a refinement of semantic mapping of elements in the functional inventory). The latter represents the final stage in the process of parametric differentiation. This third layer of the acquisition process involves the type of parametric differences where languages have comparable functional inventories, with grossly similar distributions that mask semantic differences. Examples of these differences are the present tense (Giorgi and Pianesi 1997), definiteness (Vergnaud and Zubizarreta 1992), nominal interpretation (Chierchia 1996, Dayal 2004), and arguably, number.

\subsection{The interpretation of number}

Plural markers indicate that the referent is non-atomic. In certain semantic environments this mapping of number is neutralized. For instance, generic NPs can be expressed in English by means of a bare plural, or a definite singular, as shown. Neither example makes reference to actual quantities of bats, but to the kind as a whole (Carlson and Pelletier 1995). Dependent plurals illustrate a different type of number neutralization: the singular direct object a secretary in (4a) can be interpreted directly as a singular, or as dependent on the plural subject and hence true when several secretaries were hired (Kamp and Reyle 1993). A plural object is true only of multiple entities, but it leaves unspecified how many per event, and shows comparable ambiguity: (4b) can refer to a situation where each student read a book, or many.

\section{Generic NPs}

(3) a. Bats are interesting animals.

b. The bat is an interesting animal.

Dependent plurals

(4) a. Three of the lawyers hired a secretary.

b. The students read books that kept them busy. 
These cases create a potential learning problem: the child should not simple assume a direct mapping of singular to 'one', and plural to 'many', but he/she needs to be sensitive to the whole semantic composition of the clause.

Furthermore, there is cross language variation in the distribution and interpretability of number. Leaving aside languages without number marking, such as Mandarin, and languages with polysemous mapping of number such as Farsi (Gomeshi 2003), number neutralization contexts differ across languages. For example, languages like Hungarian have incorporated bare singulars objects, as shown in (5), and these are compatible with atomic and non-atomic readings.

Incorporated nouns (Farkas and deSwart 2003)

Mari b'elyeget gy"ujt.

Mari stamp.SG.ACC collect

'Mary collect stamps/a stamp.'

Parametrization in the syntax-semantics of number can occur in related languages with very similar singular/plural contrasts. An illustration of this is the long-recognized difference in nominal syntax in Romance vs. English (Guéron 1985, 1999; Vergnaud and Zubizarreta 1992). In inalienable possession contexts, such as body parts or personal sphere nouns, number in the direct object is interpreted in relation to number on the subject. This functions as a mirror image of the interpretation of number in dependent plurals. In dependent plurals, a singular object is undetermined, but when the object is marked plural the denotation is non atomic (that is, there is more than one book in (4b)). Speakers must resolve the ambiguity of whether one or more elements of the set of books is involved in each sub-event denoted by the clause (student-reading events). In inalienable possession, the sentence is unambiguous about the quantization of the object-subject relation in each sub-event in (6), and the plurality of the possession NP is defined with respect to each possessor: (6b) refers to a plural set of heads. In neither case can number be taken directly as an expression of the atomic/non-atomic nature of the overall set denoted.

Inalienable possession

(6) a. The children shook their heads.

b. Los niños movieron la cabeza. (Spanish) the children move-PL the head-SG

c. Los niños sacudieron las piernas.

the children shook the legs

'The children shook both legs.'

Munn and Schmitt (2001) argue for systematic differences in the morphosyntax of number across these language types. They suggest that singular in Romance could be the expression of underspecified N. They point out that number underspecification is possible in Romance-type languages across contexts such as predicate nominals and part-whole constructions, as shown in the Spanish/English contrasts in (7) and (8): 
Predicate nominals

(7) Las hermanas de Luisa son todas médico.

the sisters of Luisa are all-PL doctor.

'Luisa's sisters are all doctors.'

Part/whole constructions

(8) No servirémos de testigo.

not serve-1PL of witness-SG

'We will not serve as witnesses.'

Possibly to this parametric difference, at least in some of the accounts (Vergnaud and Zubizarreta 1992), are the differences in the distribution of number in generic contexts. Romance allows definite plurals to be interpreted generically, but English doesn't.

(9) a. The dog is domesticated. (generic or non-generic)

b. The dogs are domesticated. (non-generic)

c. Los perros están domesticados. (generic or non-generic) the dog-PL be-3PL domesticated

\subsection{The acquisition of certain number neutralization contexts}

The acquisition of number interpretation is then, not as straightforward as it may first appear: not every instance of number morphology is interpretable, (as when number is an agreement marker providing redundant information), and, more importantly, there are language differences on the semantic treatment of number, as discussed above. Two recent studies have evidence that may be relevant to the issue of parametrization in number. These studies report some difficulties children may have detecting the semantic consequences of number marking in inalienable and generic contexts.

Children have shown overgeneration of inalienable readings in definite DPs in experimental conditions (Ramos 1999, Baauw 2002, Pérez-Leroux, Munn and Schmitt 2004). The results on Romance clearly document their emerging sensitivity to lexical verb constraints. Spanish speaking children discriminated between gestural motion verbs that allow inalienable readings (10a), and verbs that require reflexive marking to do so (10b), providing significantly more inalienable interpretations to cases such as (10a). The other constraint on inalienable possession is number. Plural marking on a singleton direct object is not ungrammatical, but it lacks the inalienable reading. The examples in (11b) were possible in the context, but only with the alienable reading where it referred to some toy heads. The same children who were sensitive to lexical class in the Pérez-Leroux, Munn and Schmitt (2004) study failed to restrict the inalienable interpretation when the object was pluralmarked, where such interpretation is disallowed for adults.

Lexical verb constraint

(10) a. Levantó la mano. (inalienable)

raise-3SG the hand

'(He) raised his hand.' 
b. Lavó la mano. (alienable only)

wash-3SG the hand

'(He) washed the hand.'

Number constraint

(11) a. Levantaron la cabeza. (inalienable)

raise-3PL the head-SG

'They lifted their heads.'

b. Levantaron las cabezas. (alienable only)

raise-3PL the head-PL

'They lifted the heads.'

Pérez-Leroux et al (2004) explored the acquisition of generic interpretations in another Romance/English contrast. Children in their study were presented with definite and bare plurals in contexts about atypical animals, to test for their acceptance of the generic interpretation of the subject NPs. English-speaking children in that study were able to distinguish bare plurals and definite plurals, but show persistent generic errors with definite plurals. They allowed generic readings of sentences such as (12) more than half the times.

(12) The zebras have stripes.

These results could be interpret as saying that English-speaking children's definites have the same properties of Romance definites. An alternative possibility is that children failed to interpret number and allowed the definite to be generic, just like in the English definite singular in (9a).

In sum, the acquisition of number should in principle have two distinct stages: one where the basic distribution and core meaning of the form is acquired, and another where the child must decide in what contexts in the language is number marking interpretable, in what context it is dependent, and where it is neutralized. This brief overview suggests that children may acquire early the surface distribution of number morphemes, while having incomplete knowledge of the interpretability of number at later stages.

\section{Verbal agreement in child grammar}

Some evidence shows that number agreement on verbs is early in production. English verbal agreement is \#10 in Brown's list of functional morphemes to be acquired, and the children in Brown's study reached $90 \%$ target insertion of $-s$ between 2;2 and 3;10 months (Brown 1973). An elicited production study showed that English-speaking children reach $90 \%$ target insertion by 4 in elicited production task (Rice and Wexler 2002). Data from comprehension of verbal agreement provides a contrasting picture. Fraser, Brown and Bellugi (1963) tested whether 3-year-old children were able to use the auxiliary to recover the plurality of the subject with nouns that are number-invariant, such as deer:

(13) The deer is running./The deer are running. 
A test of this contrast in a picture choice test showed that children had around 50\% accuracy, close to chance. As pointed out by Johnson et al (2004), this should be interpreted as evidence that children do not treat verbal agreement on the verb as a potentially interpretable feature. With the purpose of developing a dialect-sensitive diagnostic test for the phenomena of acquisition of $-S$ in Mainstream American English, Johnson et al (2004) and de Villiers and Johnson (2004), developed a version of this test where the plural on the noun was masked by the verb-initial sibilant. This way, number was only recoverable from the verb. They tested 3 to 6 years-old children with sentences such as (14):

(14) a. The cat sleeps on the bed.

b. The cats sleep on the bed.

Their results showed low percentages of correct responses, indistinguishable from chance in the younger children. These increase with age but are not very high over all. Statistical testing of these answers revealed 5 and 6 year olds show sensitivity to $-s$ in choosing the singular picture, but 3 and 4 year olds did not. There was a contrast between the marked and the zero form: children's. Accuracy was higher for singular sentences than for plural sentences (mean percentage of accurate responses was 52\%,64\%,79\%,74\% for 3, 45 and 6 year olds, respectively, whereas mean accuracy for the plural sentences was $42 \%, 47 \%, 61 \%, 53 \%$, respectively.

To explain the discrepancy between children's comprehension and production, Johnson and colleagues consider two possibilities, one pertinent to grammar computation, and the other to language processing. The first possibility is as follows: number marking on the verb is an uninterpretable feature that needs to be checked, but does not feed back to the subject, so they do not survive at the LF interface. Recognition of number from agreement, as a higher-level task, metalinguistic in nature, would emerge later in children. Another possibility is that, since $-s$ conflates number and person, children could not retrieve the singularity out of a feature complex, just the target distribution of it. Under this interpretation, the comprehension delay is the result of processing of particular types of morphological arrays: English verbal morphology does not uniformly represent number (only in $3^{\text {rd }}$ person), and when it does it is part of a conflated feature complex (person and number).

\section{Spanish study}

\subsection{Methods}

The same materials as Johnson et al (2004) were translated, in order to test the recoverability of number agreement in a language with a uniform, fully differentiated number agreement paradigm on the verb. In Spanish, each person has an independent morpheme marking number, as shown in table 1. The zero morpheme represents $3^{\text {rd }}$ person singular. These forms, like the English $-s$, also show conflation of number and person. 
Table 1. Agreement morphology in Spanish

\begin{tabular}{|l|l|l|l|}
\hline Person & $1^{\text {st }}$ & $2^{\text {nd }}$ & $3^{\text {rd }}$ \\
\hline Singular & $-o$ & $-s$ & $\emptyset$ \\
\hline Plural & $-m o s$ & $-i s$ & $-n$ \\
\hline
\end{tabular}

Number in Spanish is redundantly expressed in the verb and the NP, not only in the noun but in each of the nominal associates $(\mathrm{D}, \mathrm{A})$, as in (15):

(15) Los gatos negros duermen en la cama.

the cats black-PL sleep-3PL on the bed

'The black cats sleep on the bed.

The test was conducted in the Dominican Republic. In the Caribbean varieties of Spanish, number marking in nominals is an unreliable cue, because of high variability in use of syllable final $-s$. This phonological variability is the result of a sociolinguistic alternation between omission, aspiration and deletion. Plurality in NPs should be an unreliable cue, since it only reliably expressed in masculine determiners or on verbal agreement, where it has a reliable morphological expression by means of a velarized final nasal. Dominican Spanish has the highest rates of deletion among all Caribbean dialects. Miller (in preparation) had evidence that phonological variability in final -s strongly determines children's ability to interpret number in other varieties of Spanish. This makes Caribbean Spanish an excellent population for comparison with English, since number will be primarily recoverable by means of the verb rather than the nominal, independently from the experimental manipulation.

\subsection{Methods}

To mask the nominal expression of number, we used subject-drop sentences where number would be solely expressed on the verb. Tokens were then counterbalanced between a lexical subject presentation (15a) or a prodrop presentation (16). The test was a Spanish translation of the same materials. Children were shown an untimed digital presentation of pairs of picture accompanied by voice recording of sentence stimulus presented in powerpoint. Children were asked to choose the right picture for what was said, and pictures depicted singular/plural events, as shown in (17):

(15) a. El pato nada en el charco. 'The duck swims on the pond.'

(16) a. Nada en el charco. '(The duck) swims on the pond.' b. Los patos nadan en el charco. 'The ducks swim on the pond.'

b. Nadan en el charco.

'(The ducks) swim on the pond.' 
(17) Enseñame: duerme en la cama./...duermen en la cama 'Show me: (The cat) sleeps on the bed./ (The cats) sleep on the bed.

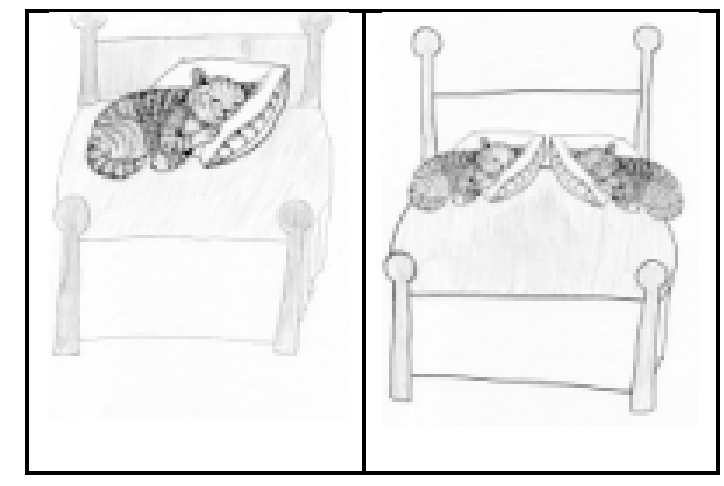

\subsection{Results}

Twenty-three children between the ages of 3 and 6 were tested in preschools in Santo Domingo, Dominican Republic. Tables 2 and 3 report mean accuracy in the picture selection task. The statistical analysis reveals a significant effect of age group: older children are more accurate than younger children $\left(\mathrm{F}_{1,21}=5.913\right.$, $p=.024)$. No other statistical effects involving sentence type or number marking were significant. Interestingly, children perform better with lexical subjects, as could be expected, but this is true only of the older children, and overall, these older children were also more accurate with the plural than the singular.

Table 2. Mean accuracy for plural and singular prodrop sentences per age group in Spanish

\begin{tabular}{lrrr} 
Group & Age range & Mean accuracy Sg & Mean accuracy Pl \\
\hline Younger $(\mathrm{N}=11)$ & $3 ; 2-4 ; 5$ & $52 \%$ & $45 \%$ \\
Older $(\mathrm{N}=12)$ & $4 ; 8-6 ; 6$ & $50 \%$ & $67 \%$
\end{tabular}

Table 3. Mean accuracy for plural and singular sentences with lexical subject per age group in Spanish

\begin{tabular}{lcrr} 
Group & Age range & Mean accuracy Sg & Mean accuracy Pl \\
\hline Younger $(\mathrm{N}=11)$ & $3 ; 2-45$ & $52 \%$ & $45 \%$ \\
Older $(\mathrm{N}=12)$ & $4 ; 8-6 ; 6$ & $67 \%$ & $79 \%$
\end{tabular}

The data from the Spanish children data are comparable to the English data in Johnson et al: there was no discrimination in 3 and 4 year-olds, and older's children accuracy increased to the $60-70 \%$ range. The different accuracy rates for singular and plural are also compatible with the English data. The morphological status of number marking in the language determines whether singular or plural will be acquired earlier. As mentioned above, Johnson and her 
colleagues found an advantage for the singular form in English, where singular is the marked form. Here we can see a plural advantage in Spanish, where plural is the marked form.

\section{Conclusions}

The present study indicates that a developmental gap in understanding number also exist in Spanish. The Spanish children's data were fully comparable to the English data in Johnson et al (2004) and deVilliers and Johnson (2004). This was so despite the more robust verbal agreement system, and the fact that the dialect has phonologically reliable expression of number on the verb but not on the NP. This suggests that acquiring a language with a uniform verbal paradigm does not improve use of number marking in comprehension for children. In this sense, these results do not support a cue-strength approach to number errors in comprehension. The results also indicate that interpretability appears first for the marked form than for the member of the paradigm express by zero morphology. The lack of morphological uniformity in the verbal paradigm cannot be the source of the comprehension difficulty, as children perform equally poorly in a language with robust verbal morphology.

This still leaves as an open question whether the source of number problems is morphological (due to conflation), syntactic (checked features) or semantic (number neutralization). In the latter case, if the children are interpreting the sentences generically, either picture is a good description of it, and what changes over time is the ability to restrict the meaning of the sentence as referring to instances and not to kinds. This is consistent with available evidence that generic readings are a semantic default.

Although ambiguous, the results in the present study underscore the need for a theory of developmental asymmetries in comprehension and production, since these children are beyond the age where there reliable insertion of the morphology is noted. Current theories of grammar have few systematic means to explain the cases where comprehension and production diverge in acquisition. I suggest here that comprehension delays are explainable under theories that take the two layers of acquisition (distribution and syntax-semantics mapping) to be separate layers of development. A child could attain surface distributions that appear grammatical, but maintain pockets of semantic underspecification. Areas of parametric variation, such as number, could be especially vulnerable to developmental delays. I would like to propose that the source of difficulty with number lies at the syntax/semantic interface. Children could master the morphology and the syntactic distribution of number marking, without arriving at a complete understanding of where number is interpretable in the language.

To the extent that this proves to be correct, the results on number delay in comprehension are compatible with a layered view of acquisition. Children who seem to set all parameters may have achieved only mastery of the distributional facts. Although number morphology is acquired early, that does not mean that children fully understand the finer-grained aspect of the semantic distribution of plural marking. 


\section{References}

Baauw, Sergio. 2000. Grammatical Features and the Acquisition of Reference. Ph.D. Dissertation, Utrecht University.

Borer, Hagit and Bernard Rohrbacher. 2002. "Minding the absent: Arguments for the Full Competence Hypothesis". Language Acquisition 102, 123-175.

Brown, Roger. 1973. A first language: The early stages. Cambridge, MA: Harvard University Press.

Carlson, Gregory N., and Pelletier, Francis. J. Eds.. 1995. The generic book. Chicago: University of Chicago Press.

Chierchia, Gennaro. 1998. "Reference to kinds across languages". Natural Language Semantics 6: 339-405.

Chomsky ,Noam. 1995. The minimalist program. Cambridge, MA: MIT Press.

Dayal, Veneeta. 2004. Number marking and indefinites in kind terms. Linguistics and Philosophy 27:4, 393-450.

De Villiers, Jill and Valery Johnson. 2004. Information in $3^{\text {rd }}$ person $-s$ : acquisition across dialects of English. Ms., Smith College and U. of Connecticut.

Farkas, Donka F. and Henriette de Swart. 2003. The Semantics of Incorporation: From Argument Structure to Discourse Transparency. Stanford: CSLI publications.

Fraser, Colin, Ursula Bellugi and Roger Brown 1963. Control of grammar in imitation, comprehension, and production. Journal of Verbal Learning and Verbal Behavior 2, 121-135.

Giorgi, Alessandra and Fabio Pianesi. 1997. Tense and aspect: from semantics to morphosyntax. New York/Oxford: Oxford University Press.

Grinstead, John. 2004. Subjects and interface delay in Spanish and Catalan. Language 80, 40-72.

Ghomeshi, Jila, 2003. "Plural marking, indefiniteness, and the noun phrase". Studia Linguistica 57, 47-74.

Guéron, Jacqueline. 1985. "Inalienable Possession, PRO-inclusion and Lexical Chains". Grammatical representation, eds. Jacqueline Guéron, Hans Georg Obenauer and Jean-Yves Pollock. Dordrecht: Foris.

Guéron, Jacqueline. 1999. Inalienable Possession. Ms., University of Paris.

Hauser, Marc, Noam Chomsky and W. Tecumseh Fitch. 2002. "The faculty of language: what is it, who has it, and how did it evolve". Science 298, 15691579.

Johnson, Valery de Villiers, Jill and Harry Seymour 2004. "Agreement without understanding: the case of the third person singular - s." Ms., U. of Connecticut, Smith College and U. of Massachusetts.

Kamp, Hans and Uwe. Reyle. 1993. From discourse to logic. Dortrech: Kluwer.

Marcus, Gary F., Vijayan, S., Bandi Rao, S., and Vishton, P. M. 1999. Rule-learning in seven-month-old infants. Science 283, 77-80.

Miller, Karen. In progress. Variable input and the acquisition of plurality in two varieties of Spanish. Ph.D. dissertation, Michigan State University.

Munn, Alan and Cristina Schmitt. 2001. "Bare Nominals and the Morpho-syntax of Number". In Current Issues in Romance Linguistics: Selected Papers from the XXIXth Linguistic Symposium on Romance Languages, eds. D. Cresti, T. Satterfield and C. Tortora, 217-231. Amsterdam: John Benjamins.

Pérez-Leroux, Ana T. 1993. Empty categories and the acquisition of Wh-movement. Amherst: GLSA. 
Pérez-Leroux, Ana T. 2003. Las restricciones gramaticales y las probabilísticas: Comentario sobre "Caminando hacia la gramática: una perspectiva teórica", por Mireia Llinàs i Grau. Cognitiva 15, 187-195.

Pérez-Leroux, Ana T., Alan Munn, Cristina Schmitt and Michelle DeIrish. 2004. Learning definite determiners: genericity and definiteness in English and Spanish. Boston University Conference on Language Development, Cascadilla Proceedings Project.

Pérez-Leroux, Ana T., Alan Munn, C. Schmitt. In preparation. Determining the: a crosslinguistic perspective on the acquisition of definite determiners

Pérez-Leroux, Ana T., Cristina Schmitt and Alan Munn. 2004. The development of inalienable possession in English and Spanish. In Romance Languages and Linguistic Theory 2002, R. Bok-Bennema, Bart Hollebrandse, B. KampersManhe and P. Sleeman, 199-216. Amsterdam: John Benjamins

Pierce, Amy. 1992. Language acquisition and syntactic theory: a comparative study of French and English grammar. Dordrecht: Kluwer.

Pinker, Steven. 1984. Language learnability and language development. Cambridge: Harvard University Press.

Ramos, Eliane. 1999. The Syntax of NPs in SLI. Ph. D. dissertation, University of Massachusetts.

Rice, M. L., and Wexler, K. 2002. Test of early grammatical impairment. San Antonio, TX: Psychological Corporation.

Saffran, J.R., Aslin, R.N., and Newport, E.L. (1996). Statistical learning by 8-month old infants. Science 274, 1926-1928.

Serratrice, L. A. Sorace and S. Paoli.. 2004. Crosslinguistic influence at the syntax-pragmatics interface: Subjects and objects in English-Italian bilingual and monolingual acquisition. Bilingualism: Language and Cognition 7, 183-205.

Tager-Flusberg, Helen. 1997. The role of theory of mind in language acquisition: contributions from the study of autism. In Research in communication and language disorders: Contribution to theories of language development, eds. L. B. Adamson and M. A. Romski, 133-158. Baltimore: Paul Brookes Publishing.

Valian, Virginia. 1990. Syntactic subjects in the early speech of American and Italian children. Cognitition 40. 21-81.

Vergnaud, Jean.-Roger. and Maria Luisa Zubizarreta. 1992. The definite determiner in French and English. Linguistic Inquiry 23, 595-652.

Verrips, Meeike. and Jürgen Weissenborn. 1992 Routes to verb placement in early German and French: the independence of finiteness and agreement. In Jürgen Meisel, ed. The acquisition of verb placement. Dordrecht: Kluwer. 